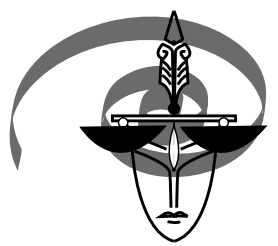

EUROPEAN

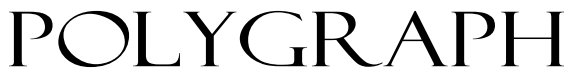

Volume $11 \cdot 2017 \cdot$ Number 4 (42)

DOI: 10.1515/ep-2017-0020

\title{
Report from the 10th Interdepartamental Polygraph Seminar Waplewo 2017
}

On 23-26 October 2017the 10th Interdepartamental Polygraph Seminar organised by the Investigations Board of the High Command of the Polish Military Police was held in the Military Leisure Centre Rewita in Waplewo (Poland). The project gathered several dozens of representatives of civilian, military, police, and special forces as well as individuals interested in the detection of deception, representing Polish academic centres and law. The subject of papers and discussions focused around candidate examinations and tests, and expertise performed for criminal trials.

Professor Ryszard Jaworski of the University of Wrocław presented an insight into the case, in which he served as an expert witness. It concerned alleged irregularities while providing an opinion from examination of a candidate to serve at the Polish Border Guard, and had charges of corruption levelled against the expert in the background. The court asked among others about the issues connected to the methodology of the examination conducted in 2003, and compliance of the expert's conduct with the procedures binding in the Border Guard as well as the assessment of information shared by the candidate and concerning his service-worthiness (Were there disqualifying facts or not?). Finally, after a trial running for over a decade, the expert was considered innocent and returned to service. The expert witness found no gross irregularities in the examination conducted, while one of the main reasons for the misunderstanding was the fact that the expert was not made familiar with the content of the candidate's previous statements, attached to the personal questionnaire, as he only assessed the information obtained at the examination. As 
far as the assessment of this information being potentially disqualifying goes, Professor Jaworski suggested a common-sense approach, especially should one consider the fact that the profile of an average candidate for non-armed services does not differ much from that of such candidate's potential superiors and representatives of the public elected in general elections. Moreover, the professor believes that an overly rigorous approach to the question of alcohol consumption or incidental use of cannabis, could cause staff shortages.

Angelika Rzeźniczak (trainee solicitor, and a doctoral student of the Frycz Modrzewski Kraków University) presented conclusions from the analysis of expert opinions concerning polygraph tests issued in the recent years in cases before the Regional Court in Kraków. She explained a number of recurring errors committed both by the party commissioning the examinations and by the expert witnesses. It turned out that the court often finds it a problem to phrase questions to the expert witness in a correct manner and, for example, requires a statement whether the subject of the test "Has an emotional connection to the case". The speaker rightly noticed that such a relationship, to a certain degree, is had by any potential subject, even the prosecutor and defence counsel. Other improperly coined phrases include "Do any memory and emotional traces concerning the deed the defender is accused of exist in his nervous system?” Instead of that Rzeźniczak suggests that the questions to the expert witness are phrased e.g. in the following manner: "Does the defendant (suspect, witness) react to the critical questions concerning [e.g. the killing of John Q. Public] in the manner usually characteristic of people providing sincere or deceptive (i.e. deceiving or hiding their knowledge of the event in question)answers?”. Optionally, should the examination be performed in the Guilty Knowledge Technique (GKT), a question concerning the information held by the subject and his or her connection to the given event: "Do the reactions of the defendant's organism suggest that he/she recognises details connected to the deed he is charged with?"

Attention was also turned to the practice, applied by some expert witnesses, of forming exceedingly long and complex critical questions in the tests, which simultaneously refer to the potential of being present in a location, committing an act, and withholding such a fact, which moreover state the place, exact date, and hour of the act. Independent of the sincerity of answers of the subject, questions thus phrased are too complicated and result in the so-called cognitive overload that in turn results in significant changes of physiological reactions in the case of both guilty and innocent individuals. Such questions can also contain inadmissible elements suggesting the answer (for example, a question whether somebody saw something that at the same time bear outs that the person was in a specific place at a specific time, which, however, is an issue that would call for a separate proof). Apart from linguistic errors, 
in some cases also the phrasing of the final conclusions leaves plenty to be wished for, especially as far as the criteria of logical cohesion, clarity, and lack of ambiguity are concerned. Moreover, there were cases when expert witnesses did not include polygrams (charts, curves) in their documentation, which rendered the appropriate expert control of the opinions issued difficult.

In the context described above, the requirement that heads of Polish courts fine tune appropriately the obligations of the expert witnesses while corroborating special information gains critical significance. The speaker proposed that a candidate for an expert witness in polygraph examination be required to produce a professional training certificate or a recommendation issued by a recognised specialist non-governmental organisation (American Polygraph Association, Polish Society for Polygraph Examinations or Polish Polygrapher Association) or any other entity of unquestioned authority (e.g. the Polish Internal Security Agency (ABW) or the Central Forensic Laboratory of the Polish Police (CLKP)). What the Polish judiciary finds a problem are a group of private expert witnesses with dubious qualifications and the phenomenon of private businesses entrusting expert opinions to subcontractors. What also remains far from being rendered precise (besides the fairly uncommon judicature) is also the notion of "specialist institution" ensconced in the codes of law (Art. $193 \$ 2$ Criminal Procedure Code). These questions should be regulated in the new Act on expert witnesses.

Przemysław Wrzosek from the Police Academy in Szczytno delivered a paper on the analysis of the subject's statements during the pre-test interview as an element supporting polygraph examination. He paid special attention to the need of including the recordings from the interview in the expert's opinion, as, should the need be, this is the only way to make the analysis of the actual statements possible. In the any other case, be it a report from the examination or minutes, all we deal with is only flawed transcription of such utterances, which can lead to incorrect conclusions.

In his lecture, Wiesław Zyskowski of the SWPS University of Social Sciences and Humanities in Warsaw, an instructor in investigation tactics and techniques with plenty of experience in serving the Polish Police and trained by the FBI, made use of a short exercise and video materials from previously conducted training sessions, and presented a sample of opportunities resulting from expert utterance and kinesics(non-verbal communication, primarily body movements)analysis. Such hints can be highly useful in practical HR recruitment and investigations.

Moreover, the participants in the seminar listened to two reports from international scientific conferences held this year in distant places: Łukasz Lep of the Polish Military Police presented an account from the conference in Astana, Kazakhstan. 
A broadside programme of polygraph examinations in police and special forces is being introduced in Kazakhstan, which results in a lively public debate. The work on an act to regulate the issue in all aspects is underway, and the standards are modelled on American ones. The only difference from the norms accepted in the Western world is lack of an option to refuse undergoing the examination without stating the reason. Such a refusal requires special conditions, such as problems of cardiologic nature and temporary problems with health.

In turn Paweł Miazga from ABW presented the most important information from the 52nd Seminar of the American Polygraph Association in Las Vegas, where 800 experts from all over the world discussed among others the conclusions from the latest scientific studies in psychophysiological examinations, the skills of conducting interviews and formulating test questions, and analysis of the data registered by polygraphs. Plenty of attention was also devoted to the physiological processes that are important while running examinations, and also to the issue of the so-called countermeasures and procedures of quality control. As far as the thematic scope of examinations is concerned, the focus was primarily on terrorism, family violence, and sex crimes.

Marcin Gołaszewski*

*biuro@ptbp.pl 